\title{
The Impact of Motivational and Metacognitive Cultural Intelligence on the Study Abroad Experience
}

\author{
Bernadette M. Racicot (Corresponding author) \\ Lerner College of Business and Economics, University of Delaware \\ 224 Alfred Lerner Hall, Newark, DE 19716, USA \\ Tel: 1-302-831-1774_E-mail: racicot@udel.edu
}

\begin{abstract}
Diane L. Ferry
Lerner College of Business and Economics, University of Delaware

219 Alfred Lerner Hall, Newark, DE 19716, USA
\end{abstract}

Tel: 1-302-831-1769 E-mail: ferryd@udel.edu

\author{
Received: February 12, 2015 Accepted: March 23, 2016 Published: March 24, 2016 \\ doi:10.5296/jei.v2i1.9021ＵRL: http://dx.doi.org/10.5296/jei.v2i1.9021
}

\begin{abstract}
The current study used a time-lagged design to examine the effects of Metacognitive and Motivational Cultural Intelligence (CQ) prior to studying abroad on the experiential behavior of students during their study abroad trip and their future interest in work and study abroad opportunities. Using Hayes' conditional process analysis, results indicated that Motivational CQ predicted Metacognitive CQ which predicted cultural experiences pursued while studying abroad which in turn predicted future interest in working/studying abroad. Implications for improving the study abroad experience and training of students for study abroad programs are discussed.
\end{abstract}

Keywords: Cultural intelligence, Motivational CQ, Metacognitive CQ, Study abroad

\section{Introduction}

Many universities offer students the opportunity to study abroad. According to the Open Doors Data portal (2016), 304,467 U.S. students participated in study abroad for credit programs in 2013-2014 with 62\% opting for programs of eight or fewer weeks in length. While students were enrolled in various fields of study, the majority were in STEM fields $(23 \%)$ business $(20 \%)$ or social sciences $(19 \%)$. Although the specific objectives of programs 
at different colleges may vary to some degree, generally, study abroad can be used to enhance learning opportunities, improve interpersonal skills, foster personal growth, and develop a deeper understanding of other cultures and international business practices (Ingraham \& Peterson, 2004: Orahood, Kruze, \& Pearson, 2004). In addition, exposure to other cultures can increase interest in other cultures which may impact students' desires to further explore cross-cultural opportunities including the desire to pursue further study abroad and future career opportunities (Norris \& Gillespie, 2009).

The study abroad literature provides some evidence that short-term study abroad experiences are valuable to students. Gullekson, Tucker, Coombs, and Wright (2011) reviewed the significant research and then went on to show that students who participated in short-term study abroad courses that focused on business consulting projects returned less ethnocentric, more culturally aware and with less intercultural communication apprehension than before they left the U.S. Another benefit commonly believed to accrue to participants of study abroad is a greater likelihood of choosing jobs and careers with an international component. Orahood et al. (2004) conducted a study to examine the impact of study abroad on future interest in careers providing international travel opportunities. They reported that students who had studied abroad for at least six weeks were more interested in cross-cultural career options and that their study abroad experience impacted their career plans. Specifically, 55\% of the students reported that the experience made a notable or significant difference in their decision to pursue careers with an international focus. Similarly, Ingraham and Peterson (2004) reported that while study abroad had a greater impact on personal growth, academic performance and intercultural awareness compared to professional development, they also indicated that studying abroad was a significant factor in student decisions to pursue international careers.

While some research suggests that these experiences are valuable to students and enable them to function more successfully in global business environments, little is understood about how to maximize the effects of study abroad or the mechanisms through which study abroad impacts behavior. We propose that cultural intelligence may be an important factor in understanding how study abroad experiences impact career choices. The purpose of the current study was to explore the impact of metacognitive and motivational cultural intelligence (CQ) on student behavior during the study abroad program and how this behavior influenced their reported interest in the opportunity to study and work abroad in the future.

\subsection{Cultural Intelligence}

Cultural Intelligence is defined as "an individual's ability to function and manage effectively in culturally diverse settings" (Ang, Van Dyne, Koh, Ng, Templer, Tay, \& Chandrasekar, 2007, p. 337). CQ is a multidimensional construct composed of four dimensions (1) Cognitive CQ refers to knowledge of other cultures including things such as values, norms, and behaviors; (2) Metacognitive CQ refers to thought processes used to interpret knowledge about other cultures; (3) Motivational CQ refers to the drive to understand and adapt to other cultures and confidence in one's ability to effectively navigate cross-cultural situations and (4) Behavioral CQ refers to the ability to interact appropriately with people from different cultures. While 
early research focused on understanding the dimensionality of the CQ construct (Ang \& Van Dyne, 2008), validating the Cultural Intelligence Scale (CQS) (Van Dyne, Ang, \& Koh, 2008) and developing conceptual models that would explain the impact of CQ on intercultural effectiveness, recent empirical research has focused more on the relationship between CQ dimensions and outcome variables.

Cultural Intelligence and its dimensions have been shown to be related to important outcome variables including problem solving style (Engle, Elahee, \& Tatoglu, 2013), negotiation effectiveness (Groves, Feyerherm, \& Gu, 2015), cultural effectiveness (Peng, Van Dyne, \& Oh, 2015), creative collaboration (Chua, Morris, \& Mor, 2012), adaptive performance (Oolders, Chernyshenki, \& Stark, 2008), work adjustment (Chen, Kirkman, Kim, Farh, \& Tangirala, 2010; Templer, Tay, \& Chandrasekar, 2006) and performance appraisal ratings (Chen et al., 2010) and sales performance (Chen, Liu, \& Portnoy, 2012).

\subsection{Dimensionality of $C Q$}

Although CQ is considered a general construct that measures the overall ability to function in diverse settings, recent research has focused on examining the relationship between the sub-dimensions of CQ and important outcome variables. Ang et al. (2007) conducted three studies to examine the impact of CQ on cultural judgment, decision making, cultural adaptation, and task performance. Results indicated that different dimensions of CQ were important in predicting the different dependent measures. Specifically, higher levels of metacognitive CQ and cognitive CQ were associated with better cultural judgment and decision making while motivational CQ was more important in predicting cultural adaptation. Both metacognitive CQ and behavioral CQ significantly improved task performance. Thus, Ang et al.'s (2007) study provides support for the idea that CQ is a multidimensional construct and that the different dimensions predict different outcome variables.

A number of other studies have examined the relationship between Motivational CQ and a number of outcome variables. Peng et al. (2015) examined the relationship between Motivational CQ and cultural effectiveness and suitability for working abroad as perceived by peers. Their results indicated that Motivational CQ scores measured prior to a study abroad program predicted cultural well-being measured two weeks after returning from the trip. Students with higher motivational CQ and cultural identity were also rated as more suitable for future work abroad opportunities by their study-abroad peers. Templer et al. (2006) studied the impact of Motivational CQ on cross-cultural adjustment. They reported that Motivational CQ significantly predicted three dimensions of adjustment (work, general, and interaction adjustment) beyond the benefits of providing realistic previews of what it would be like to work and live in an unfamiliar cultural setting. The authors suggested that further research is needed to examine the effects of other specific CQ dimensions on other outcome variables including interest and willingness to pursue other international assignments. Chen et al. (2010) examined the impact of Motivational CQ on work adjustment and job performance. Results of their study indicated that the relationship between Motivational CQ and job performance was mediated by work adjustment. The mediation relationship was stronger in the foreign subsidiaries studied when the climate was less 
supportive and more culturally distant thus supporting a moderated-mediated model. In a study of U.S. real-estate agents, Chen et al. (2012) found that individual agent Motivational CQ scores were associated with a greater number of cultural sales (sales between agents from different cultural backgrounds). They also reported that the relationship was stronger when firm-level Motivational CQ and diversity climate were stronger thereby pointing to the importance of cultural intelligence not only for expatriate employees but also for employees working in diverse settings within a single country.

A number of other studies examined the relationship between CQ and the mechanisms through which CQ impacted outcomes. Groves et al. (2015) conducted a study with 113 MBA students to examine the impact of CQ on negotiation effectiveness. Results indicated that students higher in CQ were more able to adapt their behavior to cultural nuances resulting in more effective negotiation outcomes and that the relationship between CQ and negotiation effectiveness was mediated by interest-based negotiation behaviors. Their results indicated that Cognitive and Behavioral CQ were the most important predictors of negotiation success. Lee and Sukoco (2010) examined the relationships between cultural intelligence, cultural effectiveness, cultural adjustment and expatriate performance. Their results indicated that cultural intelligence impacted expatriate performance through its effects on cultural adjustment and cultural effectiveness. Furthermore, expatriates' prior international working and travel experiences moderated the effects of CQ on cultural adjustment and cultural effectiveness indicating that previous international experience only impacted adjustment and effectiveness when CQ scores were higher. It should be noted that this study measured three dimensions of CQ, cognitive, behavioral and motivational.

These studies highlight two important points for our research (1) they suggest that a number of moderating and mediating mechanisms are important in understanding how cultural intelligence operates to impact outcomes and (2) they support the importance of examining how specific dimensions of $\mathrm{CQ}$ can be used to explain direct and indirect relationships between CQ and outcome variables.

While most of the above studies focused on motivational CQ, relatively little attention has been paid to examining the impact of metacognitive CQ on intercultural effectiveness and performance. In their study Chua et al. (2012) reported that metacognitive CQ was an important capability for enhancing creative collaboration through its impact on affect-based trust. As discussed earlier, Ang et al. (2007) found that higher levels of metacognitive CQ and cognitive CQ were associated with better cultural judgment and decision making and both metacognitive CQ and behavioral CQ significantly improved task performance. In general, research exploring the dimensions of CQ and their relationships to outcome variables appears to be somewhat varied and in need of a unifying model to help understand these complex relationships. A model proposed by Ng, Van Dyne, and Ang (2009) provides such a unifying model and is discussed below.

\subsection{Cultural Intelligence as a Learning Capability}

While the CQ research cited above examines the importance of CQ for predicting various outcome variables in cross-cultural contexts, $\mathrm{Ng}$ et al. (2009) focus on CQ as a set of learning 
capabilities. Drawing on Kolb's (1984) Experiential Learning Theory (ELT), Ng et al. (2009) suggest that CQ is an important capability in predicting how effectively people learn from their experiences while working in other cultures (Kolb, 1984, as cited in $\mathrm{Ng}$ et al., 2009).

Experiential Learning Theory describes learning as a process and emphasizes the importance of experiential learning rather than focusing solely on knowledge acquisition and behavior. According to ELT, learning involves four stages, experiencing, reflecting, thinking and acting. When someone's actions fail, s/he uses the feedback to develop new strategies to correct behavior. According to $\mathrm{Ng}$ et al. (2009), individuals differ in the extent to which they translate experience into positive outcomes. They propose that individuals who more effectively use the four stages of experiential learning will gain more valuable experience from their international assignments and further that CQ will moderate the relationship between cross-cultural experiences and learning effectiveness. Those individuals higher in CQ scores are more effective learners and in turn generate more positive outcomes from international experiences.

$\mathrm{Ng}$ et al. (2009) proposed a comprehensive model incorporating the four dimensions of CQ and the four stages of ELT. For the purpose of the present study, we chose to focus on two dimensions of CQ, Metacognitive and Motivational CQ due to our belief that these are most important to our model. According to $\mathrm{Ng}$ et al., individuals that have higher levels of Motivational CQ, because of their greater desire and confidence, will pursue more concrete experiences while working abroad, will be more likely to seek out opportunities to test their ideas and understanding of situations and will persist in the face of challenge. They also propose that higher levels of Metacognitive CQ will be associated with deeper levels of reflection involving a greater awareness of personal assumptions and beliefs, and a greater ability to use multiple perspectives when interpreting their experiences. Those higher in Metacognitive CQ are also better able to evaluate new experiences without being influenced by past experiences. Finally, individuals with higher levels of Metacognitive CQ will be more likely to develop clear plans and strategies and so will be more likely to test their ideas and understanding of situations through active experimentation.

The model proposed by $\mathrm{Ng}$ et al. (2009) provides insight into how the different dimensions of CQ operate to impact specific dependent variables. However, it does not address how specific dimensions of CQ might influence each other. For example, are individuals who are more motivated and have greater confidence in their ability to interact in diverse situations (Motivational CQ) more likely to identify avenues that would enable them to learn specific cultural norms, rituals, and practices (Cognitive CQ)? Does Motivational CQ influence one's likelihood of planning and strategizing (Metacognitive CQ) to enhance their experiences while working or studying abroad?

Van Dyne, Ang, and Livermore (2010) provide some insight into how cultural intelligence develops. They suggest that Motivational CQ provides the drive and confidence to learn about cultural differences and to plan for interactions within that culture which leads to a better understanding of cultural nuances (Cognitive CQ). Subsequently, we use Metacognitive CQ to tap into cultural knowledge which facilitates development of strategies 
for our interactions and more accurate interpretation of clues enabling us to respond with appropriate behaviors (Behavioral CQ). For the purpose of the current study, we focused on the link between Motivational CQ and Metacognitive CQ. Our rationale is that developing strategies, carefully observing the conduct of those around us and thinking about how we are thinking and interpreting others' behavior (Metacognitive CQ) takes more time and energy and a greater belief in our ability to correctly interpret our experiences. Therefore, it would seem that Motivational CQ (drive and self-confidence) would be very important in developing and using metacognitive skills. For our sample, we did not expect that cognitive and behavioral CQ would vary because the students had little or no previous experience in working or studying abroad.

\section{The Current Study}

Previous research suggests that study abroad impacts future career interests; however, there are differences among students with respect to the impact of study abroad on their choices. Although more than 50\% of students in Orahood et al.'s (2004) study reported a significant impact of study abroad programs on career choices, there were obviously many who were not as greatly influenced. We suggest that the concept of Cultural Intelligence as a learning capability provides a useful framework for examining the mechanisms through which study abroad impacts future career interests. Specifically, we propose that Motivational CQ and Metacognitive CQ and their influence on behavior during study abroad can help explain why some students are more influenced to pursue future cross-cultural experiences than others. Templer et al. (2006) suggest that people higher in Motivational CQ are more open to novel experiences and exploring opportunities to try new things. Therefore, it makes sense that people higher in Motivational CQ would pursue more different experiences while studying abroad than those less motivated. We further propose that they will only engage in this behavior if they feel confident in their ability to plan and strategize for cross-cultural interactions, that is, they have higher Metacognitive CQ.

\subsection{Hypothesized Model}

We hypothesize that students higher in Motivational CQ, due to their greater desire and confidence, will develop better plans and strategies for dealing with experiences while studying abroad (higher levels of Metacognitive CQ) which will lead them to pursue more cultural experiences during their study abroad trip which will influence future interest to work/study abroad (See Figure 1).

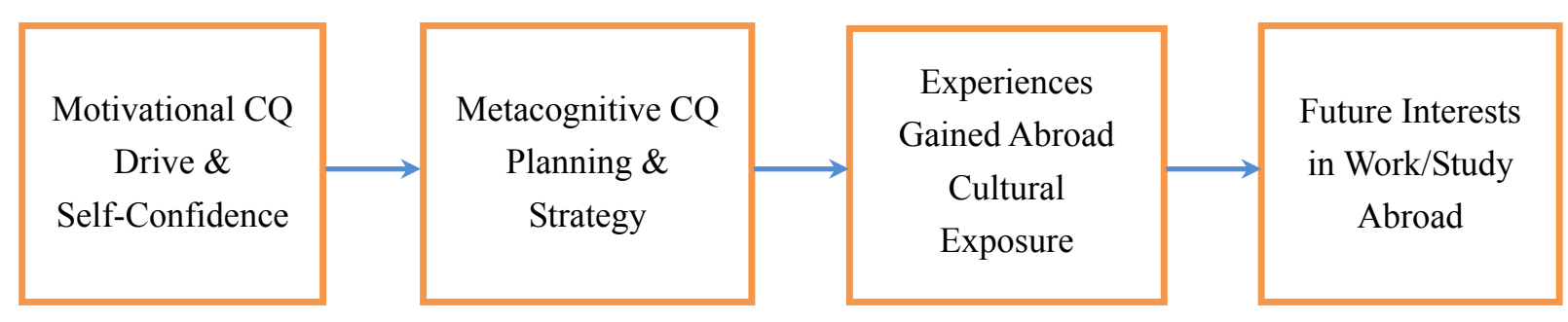

Figure 1. Hypothesized model 


\section{Method}

\subsection{Participants}

Participants were 60 undergraduate students from a large public university in the United States mid-Atlantic region enrolled in four different study abroad courses held during a five-week winter term. Thirty-nine students were enrolled in business classes, 11 students were enrolled in a criminal justice class, and 10 students were enrolled in a kinesiology and applied physiology class. Students attended classes in either one or two countries that were predominantly English-speaking (16 students studied in Australia and New Zealand; 11 students in London; 10 students in New Zealand and 23 students in Australia and Singapore). The age of students ranged from 19-22 (Mean age $=20.47$ ). Forty-two students were female and 18 were male. Thirty-four of the students were juniors, 21 were seniors and 5 were sophomores. The majority of the students were born in the United States $(\mathrm{N}=55)$ compared with 5 students born outside of the U.S. The majority of students had traveled abroad for vacation $(\mathrm{N}=49)$ while fewer traveled for volunteer work $(\mathrm{N}=6)$ or education $(\mathrm{N}=12)$. Students reported a moderate amount of overall travel experience (Mean $=3.62$ on a 7-point scale ranging from no travel experience to extensive travel experience).

Each study abroad course was part of a specific study abroad program; each program consisted of two courses. Each course included content consistent with its course designation, such as marketing, management, accounting and MIS, kinesiology and applied physiology, and criminal justice.

A typical day for each program included classes and/or visits to relevant companies or organizations to learn more about how the respective fields were handled in the different international settings. Visits to companies and organizations included presentations, tours, and question and answer sessions led by practitioners. For example, the business programs required students to prepare in their off-time for visits by researching the companies and organizations they would visit and reporting their research findings to the other members of the class. When the class made their visit, students were then prepared to ask questions and take notes regarding marketing and management practices. Students typically spent Monday through Thursday or Friday making company visits to engage with local practitioners to learn how they carry out their primary operations in the local environment. In each program three to four culturally oriented excursions were included as part of the program, for example, trips to local attractions, museums, or festivals. Students were free from program commitments for the two or three day weekends, as well as most weekday evenings giving them time to explore the local cultures on their own. To remove the possibility of students' facility with the local language holding them back from cultural exploration, only English-speaking programs were selected for inclusion in our study.

\subsection{Measures}

Metacognitive CQ and Motivational CQ were measured using items from the previously validated CQS-20 scale (Ang et al., 2007; Van Dyne et al., 2008). The Metacognitive CQ scale contains four items and the Motivational CQ scale contains five items. Sample items for 
the Metacognitive CQ scale include "I am conscious of the cultural knowledge I use when interacting with people with different cultural backgrounds" and "I adjust my cultural knowledge as I interact with people from a culture that is unfamiliar to me." Sample items for Motivational CQ scale include "I enjoy living in cultures that are unfamiliar to me" and "I am confident that I can socialize with locals in a culture that is unfamiliar to me." All items were measured using a seven-point Likert Scale ( $1=$ strongly disagree; $7=$ strongly agree). Cronbach's alpha for the Metacognitive and Motivational CQ scales were .80 and .76, respectively. Students were asked to indicate their extent of previous international travel on a 7-point scale ( 1 = no international travel; $7=$ extensive international travel) and to indicate whether they had traveled abroad for vacation, volunteer work or education (measure adapted from Caligiuri \& Tarique, 2012). Students were also asked to provide demographic data including age, gender, year in school, and whether or not they were born in the United States. These measures were completed prior to students leaving for their study abroad program.

Upon return from the study abroad program, students were asked to complete measures relating to their experience during their program and future interest in studying/working abroad. Three items were used to assess the degree to which they participated in cultural experiences while abroad (Cronbach's alpha $=.58$ ). Sample items include "I spent a great deal of time exploring the uniqueness of the host country" and "I enjoyed visiting local attractions that were unique to the host country." Two items were used to evaluate future interest in working and studying abroad ("Given the opportunity, I would participate in another study abroad experience" and "Based on my experience, I would like to pursue job opportunities that would enable me to travel abroad"). These two items were intercorrelated $(r=.52)$.

\subsection{Procedure}

A time-lagged design was used to assess the impact of Metacognitive and Motivational CQ on the experiences pursued while studying abroad and future interest in working/studying abroad. Approximately 2 months prior to leaving, with permission from the study abroad professors and the University Institute for Global Studies, students were invited to attend a session with the researchers to complete the CQ scales. Students were told that the purpose of the research was to study cultural perceptions. They were told that participation was voluntary and those that chose to participate were asked to sign an informed consent document. They were also told that upon return from their study abroad program, they would be asked to complete an on-line survey that included the questions regarding their experiences and future interest in working and/or studying abroad. In order to provide an incentive to complete the surveys, students were told that they would be eligible for a lottery where ten students that completed both surveys would be randomly chosen to receive a $\$ 100$ gift card. A total of 106 students completed the time 1 survey (100\% participation).

Approximately 4 weeks after returning from the study abroad trip, all of the students who completed the time 1 survey were sent an e-mail with a Qualtrics link to the electronic survey. Reminder e-mails were sent at one and two week intervals. A final e-mail was sent two days prior to the closing date of the survey. A total of 60 students completed the survey at time 2 . 


\section{Macrothink}

One student who failed to complete all items on the time 2 survey was eliminated from the data analyses. Response rate at time two was $54 \%$.

\section{Results}

Descriptive statistics and zero-order correlations for the study variables are provided in Table 1. All correlations were in the expected direction. Since previous travel experience was correlated with one of the model variables, Motivational CQ, this variable was included as a control variable in the data analyses discussed below.

Mediation analysis was used to examine the indirect effect of Motivational CQ on interest in pursuing future work and study abroad opportunities through the mediating effects of Metacognitive CQ and experiences gained while studying abroad (see Figure 1). In order to test the model, conditional process analysis was used (Hayes, 2013). Hayes' method uses an ordinary least squares path analytic framework for assessing indirect and direct effects in multiple mediation models. It also provides bootstrap and Monte Carlo confidence intervals that can be used to evaluate model fit. Bootstrap confidence intervals that do not contain zero are considered a good fit to the data while confidence intervals that contain zero are not considered a good fit.

Results of the mediation analysis are presented in Table 2. In step 1 of the mediation analysis, Metacognitive CQ was regressed on Motivational CQ and the covariate (Travel Experience). Results indicated that Motivational CQ was a significant predictor of Metacognitive CQ $(t=$ 3.28, $p<.01)$. In step 2, Experiences Gained was regressed on Motivational CQ and Metacognitive CQ and the covariate. As predicted, only Metacognitive CQ was significant in predicting Experiences Gained $(t=.226, p<.05)$ while Motivational CQ was non-significant $(t=1.36, p>.05)$. In step 3, Future Interest in Work/Study Abroad was regressed on Motivational CQ, Metacognitive CQ, and Experiences Gained. As predicted only Experiences Gained was a significant predictor of future interests $(t=2.57, p<.05)$. It should be noted that the covariate (previous travel experience) was not significant in any of the regression analyses. 
Table 1. Descriptive statistics and zero-order correlations for model variables

\begin{tabular}{|l|l|l|l|l|l|l|l|}
\hline & M & SD & 1 & 2 & 3 & 4 & 5 \\
\hline 1. Metacognitive CQ & 4.48 & 0.91 & 1.00 & \multicolumn{5}{|l|}{} \\
\hline 2. Motivational CQ & 5.02 & 0.81 & $.41^{* *}$ & \multicolumn{5}{|l|}{} \\
\hline 3. Experiences abroad & 6.50 & 0.57 & $.37^{* *}$ & $.35^{* *}$ & \multicolumn{5}{|l|}{} \\
\hline 4. Future work/study abroad & 6.45 & 0.70 & .22 & $.27^{*}$ & $.43^{* *}$ & & \\
\hline 5. Travel experience & 3.62 & 1.63 & .13 & $.26^{*}$ & .23 & .22 & \\
\hline
\end{tabular}

Note. ${ }^{*} p<.05 ; * * p<.01$.

Table 2. Least squares regression results for model variables

\begin{tabular}{|l|l|l|l|l|l|l|}
\hline & \multicolumn{2}{|c|}{ Equation 1 } & \multicolumn{2}{c|}{ Equation 2 } & \multicolumn{2}{c|}{ Equation 3 } \\
\hline & \multicolumn{2}{|c|}{ Metacognitive CQ } & \multicolumn{2}{c|}{ Experiences Gained } & \multicolumn{2}{c|}{$\begin{array}{c}\text { Future Interest-Work/ } \\
\text { Study Abroad }\end{array}$} \\
\hline Predictors & $\mathrm{b}$ & $\mathrm{t}$ & $\mathrm{b}$ & $\mathrm{t}$ & $\mathrm{b}$ & $\mathrm{t}$ \\
\hline Motivational CQ & .462 & $3.281^{* *}$ & & & & \\
\hline Metacognitive CQ & & & .188 & $2.260^{*}$ & & \\
\hline Motivational CQ & & & .130 & 1.360 & & .038 \\
\hline Metacognitive CQ & & & & & .432 & $2.57^{*}$ \\
\hline Experiences Gained & & & & & .088 & .727 \\
\hline Motivational CQ & & & & & & \\
\hline
\end{tabular}

Note. $*=p<.05, * *=p<.01 ; \mathrm{b}=$ unstandardized regression coefficients.

Tests of direct and indirect effects supported the hypothesized model. Tests of direct effects of Motivational CQ on Future Interests in Work/Study Abroad were non-significant $(t=.73$, 
$p>.05)$. Model fit was assessed using the bootstrap/Monte Carlo results. A comparison of the three potential mediation models indicated that the model that included both mediators (Metacognitive CQ and Experiences Gained) was a better fit to the data (LLCI $=.0072$; ULCI $=.1313$ ) than either of the models containing a single mediator (LLCI $=-.1260$, UCLI $=.2083$; LLCI $=-.0074$, ULCI $=.2002$ for models containing Metacognitive CQ or Experiences Gained alone, respectively).

\section{Discussion}

Results of the current study suggest that both Motivational CQ and Metacognitive CQ are important in understanding the relationship between study abroad experiences and interest in future careers with an international component. Furthermore, results of the mediation analysis indicate that the two dimensions of CQ may operate in a sequential manner whereby Motivational CQ stimulates the development and testing of plans and strategies for navigating the study abroad experience (Metacognitive CQ) to influence the experiences pursued during study abroad and ultimately interest in future study abroad/work abroad opportunities.

Our results are consistent with findings reported in the literature. For example, Peng et al. (2015) reported that motivational CQ was positively related to cultural effectiveness. Several other researchers have also reported significant relationships between Motivational CQ and important outcome variables including performance and cultural adjustment (Chen et al., 2010; Chen et al., 2012; Templar et al., 2006). Our results extend these findings by exploring how Metacognitive CQ and Motivational CQ operate together to influence behavior and intentions (i.e., interest in future study/work abroad).

\subsection{Implications for Study Abroad Programs}

Although, study abroad programs have become increasingly popular, their effectiveness has rarely been systematically and thoroughly evaluated (Pedersen, 2010). Furthermore, the mechanisms through which study abroad impacts outcomes such as career decisions have been overlooked. The findings of the current research could provide some ideas for universities to help students capitalize on their study abroad experiences, especially since organizations are not only more global, but also more diverse within the United States. Employees will be increasingly required to understand how to work effectively with people from different backgrounds and cultures.

If Motivational CQ and Metacognitive CQ are important components in determining how fully students experience new cultures while abroad and further, also impact career choices, universities should consider interventions that would enhance their programs. Identifying students who are more motivated for study abroad might result in students who have a greater likelihood of adjusting to and maximizing the study abroad experience. However, given the need for students to work and study in diverse environments it would seem that we should encourage as many students as possible to engage in and benefit from study abroad programs. Alternatively, providing students who show interest in study abroad with pre-departure information that would improve Motivational CQ may be a more beneficial solution. This 
idea has been previously endorsed by both study abroad administrators and researchers. As suggested by Peng et al. (2015) providing students with pre-departure interventions that would increase their knowledge of the countries that they will visit might be important in motivating them to learn more about the culture. Perhaps, providing structured educational sessions about local cultures and the contributions of those cultures to society would enhance motivation to explore and more fully engage during their study abroad trips.

In a review of the intercultural training literature, Earley and Peterson (2004) agree that both experience and information are important to successful completion of international assignments. However, they point to the fact that most training programs focus solely on the cognitive aspects of improving intercultural competence. They further suggest that it is faulty to assume that trainees can transfer the learning acquired in training, including experiential learning, to actual international assignments and experiences. According to Earley and Peterson, people have limited ability to make those leaps unless metacognitive strategies are included in the training. Given that organizations are increasingly sending employees on short-term international assignments, it is important that they be able to adapt quickly in order to be successful. Early and Peterson (2004) suggest that the CQ model can be used to improve intercultural training. They argue that while knowledge of other cultures is important, the metacognitive and motivational components are most important in improving performance in multinational teams.

Although the Early and Peterson (2004) article focused on employee effectiveness, their suggestions would also apply to students engaging in short-term study abroad programs where students have little time available to adapt to the new culture or cultures and are expected to perform effectively within a short period of time. We suggest that providing assistance that would improve their ability to put that knowledge to use (Metacognitive CQ) is also important. Providing training in metacognitive strategies for students prior to study abroad might improve their ability to interact more effectively in unfamiliar settings thus encouraging them to engage more fully during their study abroad experience. Pedersen (2010) provides data to support this assertion. The study found that students who were exposed to diversity training, including guided reflection which is critical to metacognition, scored higher in intercultural sensitivity after study abroad compared to students who did not receive the training. They conclude that sending students abroad to study is not enough to create global citizenship. Preparation and intercultural pedagogy is critical to the success of such programs.

\section{Limitations and Suggestions for Future Research}

Although we found that Metacognitive CQ was significant in predicting experiences pursued while abroad and career choice intentions, we need to understand more about how metacognition operates for study abroad students. Future research should explore how strategies and planning differ for those higher in Metacognitive CQ. One avenue for assessing strategy is to ask students what types of strategies they plan to use to approach their study abroad experience. Perhaps, students could also be required to maintain journals which could be analyzed for depth of reflection. Further research into the antecedents of Motivational CQ 
would also be useful. For example, researchers could examine the impact of pre-departure intercultural education on Motivational CQ and the resulting impact on behavior during study abroad and post-study abroad career choices. In addition, future research should focus on the actual career choices made using a longitudinal research design. The current study is limited by the measure of career choice intentions. Although intentions may influence behavior, actual measures of career choices would make a stronger statement. Additional research should explore the relationship between the dimensions of cultural intelligence and how they operate together to impact important outcome variables related to intercultural effectiveness. Finally, future research could explore how study abroad impacts effectiveness in domestic employment situations particularly how motivational CQ and metacognitive CQ contribute to success in working in diverse work environments.

As with all research, the current study is not without limitations. We focused on programs in countries that were primarily English-speaking which may have made it easier for students to explore cultural opportunities. In addition, our sample size was relatively small due to the response rate for the survey conducted post study-abroad. Since the second survey was conducted at the beginning of the Spring semester, it is possible that students were busy with classes and did not have time to respond, even though we did provide them with ample time and several reminders. It is conceivable that non-responders from the time 2 survey differed in their behavior and future interests, therefore a larger sample size could provide increased confidence in our findings. Finally, it should be noted that the study abroad programs are well-designed and that is certainly a factor in cultural adjustment that is supported by the relatively high average scores for experiences pursued and future interest in working and studying abroad.

\section{References}

Ang, S., \& Van Dyne, L. (2008). Conceptualizations of cultural intelligence: Definition, distinctiveness, and nomological network. In S. Ang \& L. Van Dyne (Eds.), Handbook of Cultural Intelligence: Theory, measurement and applications (pp. 3-15). Armonk, NY: M. E. Sharpe.

Ang, S., Van Dyne, L., Koh, C., Ng, K. Y., Templer, K. J., Tay, C., \& Chandrasekar, N. A. (2007). Cultural intelligence: Its measurement and effects on cultural judgment and decision making, cultural adaptation and task performance. Management and Organization Review, 3(3), 335-371. http://dx.doi.org/10.1.org/11/j.1740-8784.2007.00082.x

Caligiuri, P., \& Tarique, I. (2012). Dynamic cross-cultural competencies and global leadership effectiveness. Journal of World Business, 4(2), 612-622. http://dx.doi.org/10.1016/j.jwb.2012.01.014

Chen, G., Kirkman, B. L., Kim, K., Farh, C. I. C., \& Tangirala, S. (2010). When does cross-cultural motivation enhance expatriate effectiveness? A multilevel investigation of the moderating roles of subsidiary support and cultural distance. Academy of Management Journal, 53(5), 1110-1130. http://dx.doi.org/10.5465/AMJ.2010.54533217

Chen, X., Liu, D., \& Portnoy, R. (2012). A multilevel investigation of motivational cultural 
intelligence, organizational diversity climate, and cultural sales: Evidence from U.S. real estate firms. Journal of Applied Psychology, 97(1), 93-106. http://dx.doi.org/10.1037/ a0024697

Chua, R. Y. J., Morris, M. W., \& Mor, S. (2012). Collaborating across cultures: Cultural metacognition and affect-based trust in creative collaboration. Organizational Behavior and Human Decision Processes, 118(2), 116-131. http://dx.doi.org/10.1016/j.obhdp.2012.03.009

Early, P. C., \& Peterson, R. S. (2004). The elusive cultural chameleon: Cultural intelligence as a new approach to intercultural training for the global manager. Academy of Management Learning and Education, 3(1), 100-115. http://dx.doi.org/10.5465/AMLE.2004.12436826

Engle, R. L., Elahee, M. N., \& Tatoglu, E. (2013). Antecedents of Problem-Solving Cross-Cultural Negotiation Style: Some Preliminary Evidence. The Journal of Applied Management and Entrepreneurship, 18(2), 83-102. http://dx.doi.org/10.9774/GLEAF.370 9.2013.ap.00007

Groves, K. S., Feyerherm, A., \& Gu, M. (2015). Examining cultural intelligence and cross-cultural negotiation effectiveness. Journal of Management Education, 39(2), 209-243. http://dx.doi.org/10.1177/1052562914543273

Gullekson, N. L., Tucker, M. L., Coombs, Jr. G., \& Wright, S. B. (2011). Examining intercultural growth for business students in short-term study abroad programs: Too good to be true? Journal of Teaching in International Business, 22(2), 91-106. http://dx.doi.org/10.1080/08975930.2011.615672

Hayes, A. F. (2013). Introduction to Mediation, Moderation, and Conditional Process Analysis: A Regression-Based Approach. Guilford Press.

Ingraham, E. C., \& Peterson, D. L. (2004). Assessing the Impact of Study Abroad on Student Learning at Michigan State University. Frontiers: The Interdisciplinary Journal of Study Abroad, 10, 83-100.

Kolb, D. A. (1984). Experiential learning: Experience as the source of learning and development. Englewood Cliffs, NJ: Prentice-Hall.

Lee, L., \& Sukoco, B. M. (2010). The effects of cultural intelligence on expatriate performance: the moderating effects of international experience. The International Journal of Human Resource Management, 21(7), 963-981. http://dx.doi.org/10.1080/095851910037 83397

Ng, K., Van Dyne, L., \& Ang, S. (2009). From experience to experiential learning: Cultural intelligence as a learning capability for global leader development. Academy of Management Learning and Education, 8(4), 511-526. http://dx.doi.org/10.5465/AMLE.2009.47785470

Norris, E. M., \& Gillespie, J. (2009). How study abroad shapes global careers: Evidence from the United States. Journal of Studies in International Education, 13(3), 382-397. http://dx.doi.org/10.1177/1028315308319740 


\section{Macrothink}

Oolders, T., Chernyshenki, O. S., \& Stark, S. (2008). Cultural intelligence as a mediator of relationships between openness to experience and adaptive performance. In S. Ang, \& L. Van Dyne (Eds.), Handbook of Cultural Intelligence: Theory, measurement and applications (pp. 145-158). Armonk, NY: M. E. Sharpe.

Open Doors. (2016). Open doors data. Retrieved from http://www.iie.org/research-and-publications/open-doors/data/us-study-abroad

Orahood, T., Kruze, L., \& Pearson, D. E. (2004).The impact of study abroad on business students' career goals. Frontiers: The Interdisciplinary Journal of Study Abroad, 10, 117-130.

Pedersen, P. J. (2010). Assessing intercultural effectiveness outcomes in a year-long study abroad program. International Journal of Intercultural Relations, 34(1), 70-80. http://dx.doi.org/10.1016/j.ijintrel.2009.09.003

Peng, A. C., Van Dyne, L., \& Oh, K. (2015). The influence of motivational cultural intelligence on cultural effectiveness based on study abroad: The moderating role of participant's cultural identity. Journal of Management Education, 39(5), 572-596. http://dx.doi.org/10.1177/1052562914555717

Templer, K. J., Tay, C., \& Chandrasekar, N. A. (2006). Motivational cultural intelligence, realistic job preview, realistic living conditions preview, and cross-cultural adjustment. Group and Organization Management, 31(1), 154-173. http://dx.doi.org/10.1177/10596011052 75293

Van Dyne, L., Ang, S., \& Koh, C. (2008). Development and Validation of the CQS the cultural intelligence scale. In S. Ang, \& L. Van Dyne (Eds.), Handbook of Cultural Intelligence: Theory, measurement and applications (pp. 16-38). Armonk, NY: M. E. Sharpe.

Van Dyne, L., Ang, S., \& Livermore, D. (2010). Cultural intelligence: A pathway for leading in a rapidly globalizing world. In K. M. Hannum, B. McFeeters, \& L. Booysen (Eds.), Leadership across differences: Cases and perspectives (pp. 1-13). San Francisco, CQ: Pfeiffer.

\section{Copyright Disclaimer}

Copyright for this article is retained by the author(s), with first publication rights granted to the journal.

This is an open-access article distributed under the terms and conditions of the Creative Commons Attribution license (http://creativecommons.org/licenses/by/3.0/). 